\title{
The Role of the Internet Technology in the Employment Structural Transformation under Background of "Internet Plus" in China
}

\author{
Weicheng $\mathrm{Xu}^{1,2^{*}}$, Caiyun Zhao ${ }^{1}$, Xiao Wang1 \\ ${ }^{1}$ School of Economics, Ocean University of China, Qingdao, China \\ ${ }^{2}$ Institute of Marine Development, Ocean University of China, Qingdao, China \\ Email: *weicheng.xu@163.com
}

How to cite this paper: $\mathrm{Xu}, \mathrm{W}$. C., Zhao, C. Y., \& Wang, X. (2021). The Role of the Internet Technology in the Employment Structural Transformation under Background of "Internet Plus" in China. Theoretical Economics Letters, 11, 1020-1037. https://doi.org/10.4236/tel.2021.115065

Received: August 20, 2021

Accepted: October 26, 2021

Published: October 29, 2021

Copyright $\odot 2021$ by author(s) and Scientific Research Publishing Inc. This work is licensed under the Creative Commons Attribution International License (CC BY 4.0).

http://creativecommons.org/licenses/by/4.0/

\section{(c) (i) Open Access}

\begin{abstract}
This paper investigates the role of the internet technology in explaining the process of employment structural transformation under background of "Internet Plus" in China. We develop an employment structural transformation model which is impacted by the substitution effect and pervasiveness effect of internet technology, and show that the sectoral reallocation of employment out of agriculture and manufacturing into services when the substitution between manufacturing and service goods is too elastic and the internet technology penetration to total factor productivity of services is greater than the penetration of manufacturing. Our further empirical analysis confirms the conclusion deduced by the model. These results verify the "Internet Plus" plan can promote the productivity and accelerate the employment structural transformation and upgrading in China.
\end{abstract}

\section{Keywords}

Internet Technology, Structural Transformation, Substitution Effect, Penetration Effect

\section{Introduction}

The "Internet Plus" action plan was officially unveiled in the 2015 China Government Work Report, which represents a new economic form. "Internet Plus" strategy means integrating internet technology with other industries including traditional industries through internet platform and information and communication technologies. The integration of Internet with the traditional industries has a deep influence on the development of the traditional industries, like agriculture, manufacturing and services industry especially, which is prominently 
manifest in the process of structural change. Structural change is not only reflected in the change of output and productivity, but also in the change of factor input sets in the production process (Jorgenson \& Timmer, 2011; Li et al., 2019). One of the most significant characteristics is the changes in labor shares across three sectors.

The labor reallocation across industries over time is typically referred to as the structural transformation in the economic development literature, and this process has been widely documented (Kuznets, 1973; Duarte \& Restuccia, 2010). Along the modern paths of development, China undergoes a process of structural transformation by which labor is reallocated among agriculture, manufacturing, and services. Since the reform and opening up of China, the shares of labor in agriculture fell from $70.5 \%$ to $26.1 \%$ in 2018 , while the share of labor in services rose from $12.2 \%$ to $46.3 \%$ (see Figure 1). This paper will focus on the role of internet technology in the employment structural transformation under the background of "Internet Plus" in China.

The earlier structural research can be traced back to the seminal contribution of Baumol (1967), who constructs a model including "progressive" sector and "non-progressive" sector. In addition to the famous "Baumol's cost disease", this paper also finds that the labor will move in the direction of the non-progressive sector if the ratio of the outputs of the two sectors is held constant. Based on the early research of Baumol (1967), related literature has identified several mechanisms that can drive structural change. Current studies on structural transformation can be classified into two categories, one is to emphasize the demand-side channel which highlights the income elasticity of demand heterogeneity across goods (Kongsamut et al., 2001; Foellmi \& Zweimüller, 2008; Boppart, 2014; Song et al., 2020). The other is to highlight the supply-side channel where the differences of the total factor productivity (TFP) across sectors play the central role (Ngai \& Pissarides, 2007; Acemoglu \& Guerrieri, 2008; Mao \& Yao, 2012).

Technology progress can trigger economic growth and productivity growth, and it also can trigger structural transformation (Acemoglu \& Guerrieri, 2008). Information technology (IT) is an important part of it, and its effects have received considerable attention in recent years. Information technology has a fundamental influence on U.S. economic resurgence in the early stage of development (Jorgenson et al., 2008). Information technology has spawned the beginning of the digital economy, and IT has become the core technology of contemporary social and economic development.

As an important representative in the era of IT and a new economic form, we must pay full attention to the role of internet technology. Widely use and deeply participation in internet technology not only can promote innovation across industries, but also can improve economic efficiency (Andersen, 2001). A large body of researches focus on the impact of internet technology, and also many 


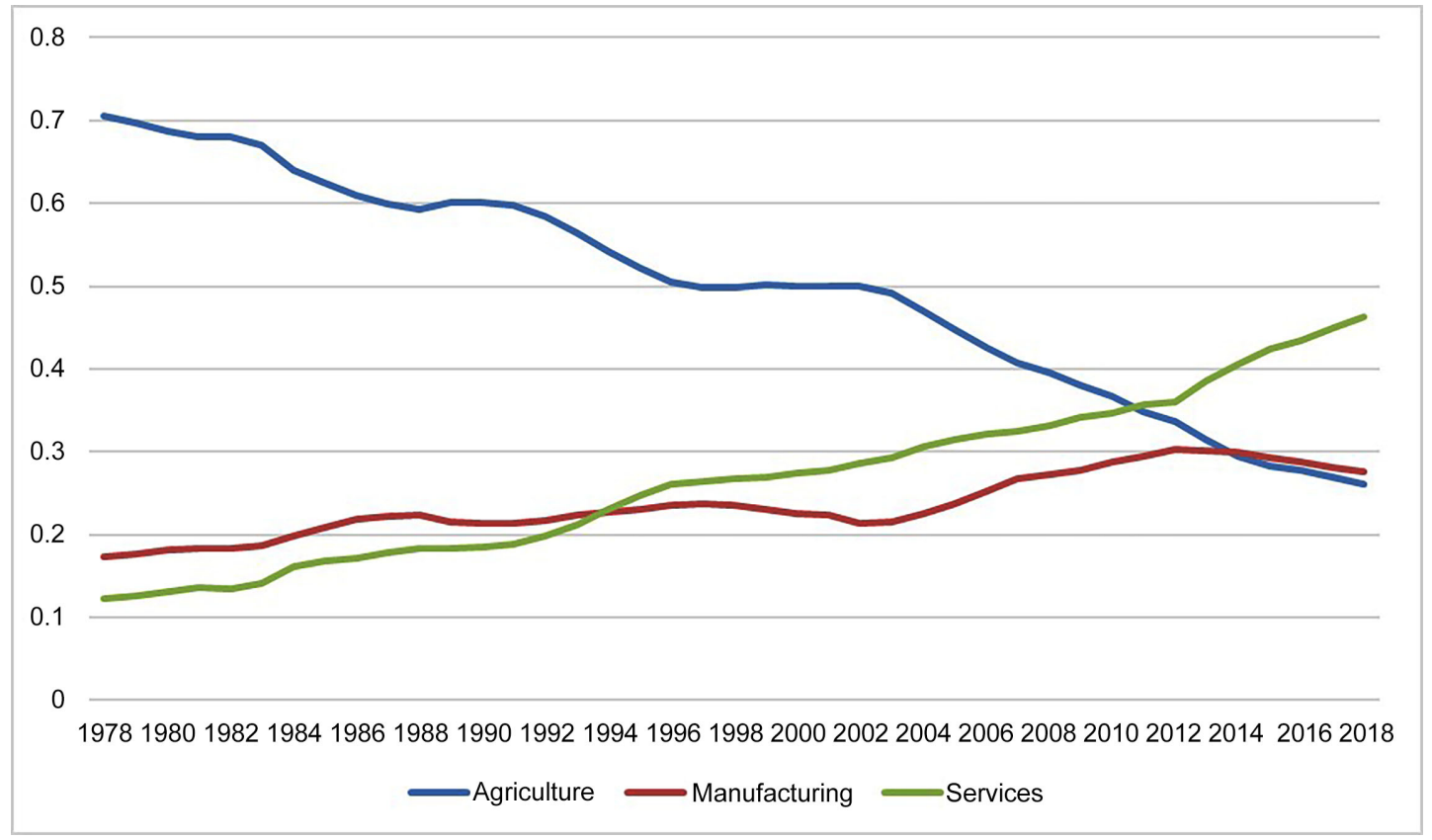

Figure 1. The shares of employment of China by three sectors, 1978-2018.

researches focus on the structural change driven by technology progress and productivity improvement. However, relatively little attention has been paid to how the internet technology directly affects structural change, and then reveals the mechanisms of structural transformation. Our paper aims to expand the classic papers of Ngai \& Pissarides (2007) and Duarte \& Restuccia (2010) to argue that the relationship between technology progress, productivity growth and structural change. And our study is based on the example of the Chinese economy.

To address this issue, we begin by developing a model of the employment structural transformation across three sectors driven by the internet technology. The non-homotheticity of preference over agriculture goods leads to the movement of labor away from agriculture in the process of employment structural transformation as the internet technology improvement, which is consistent with the shares of labor distribution data in China. In addition, we extend the framework proposed by Duarte \& Restuccia (2010) to account for the role of the internet technology penetration in the analysis. This is important because it allows us to answer two key questions. First, how important is the development of internet technology in causing the employment structural transformation across sectors? Second, what are the main causes of the differences of sectoral labor share changes? This is also the main contribution and innovation of this paper. This study represents the first empirical analysis of the penetration of the internet technology influencing employment share change in China. The substitution effect and the pervasiveness effect of internet technology were introduced to analyze the influence of internet technology penetration on the employment structural change, which is different from existing research. 
Based on the internet technology estimated by Solow residual method, the regression models of productivity and internet technology show that the penetration of internet technology to TFP of services exceeds the manufacturing. And we also discuss the substitution effect generated by the internet technology, and illustrate that the substitution between manufacturing and service goods is too elastic by corresponding sectoral data in China. Then we deduce that the internet technology improvement should lead to the reallocation of labor from agriculture and manufacturing into services according to the proposition of the model.

To confirm the essential link between internet technology and structural change, the paper contains an empirical analysis to outline the theoretical model of the impact of internet technology progress has on labor reallocation, by taking the model to the data for 31 provinces in China over the period 2003-2018. We find that the improvement of internet technology will lead to the reallocation of labor from agriculture and manufacturing into services, the internet technology improvement $1 \%$ could be associated with an increase in employment ratio of services to manufacturing around $0.445 \%$ - $0.585 \%$ in China. The empirical results confirm the conclusions obtained from the model.

The rest of this paper proceeds as follows. The next section outlines the literature review. Section 3 describes a general equilibrium model of the employment structural transformation which is driven by internet technology. Section 4 evaluates the substitution effect and pervasiveness effect of internet technology. Section 5 is the empirical design and analysis. Finally, Section 6 concludes.

\section{Related Literature}

The changes in reallocation of labor shares over the last several decades have motivated many researches investigating the linkage between technical change and structural transformation. Technology can be seen as a factor-augmenting form, which is also a supplement to high or low skill labor (Acemoglu \& Autor, 2011). A number of studies have been concerned with the connection between technology progress and structural transformation. Our analysis sheds further light on this topic by inspecting the influences of internet technology in a context of rapid technology progress.

The link between technology progress, productivity improvement and structural change is a topic that is very controversial and high on the research agenda. Fagerberg (2000) highlights the relationship between productivity growth and structural transformation from the perspective of technological progress, and concludes that labor in industries with advantages in new technologies increases rapidly. Ngai \& Pissarides (2007) shows that the differences of TFP growth rates across sectors drive the changes of sectoral labor shares, and the results are consistent the observations and previous evidences. Duarte \& Restuccia (2010) investigate the effect of sectoral labor productivity on the structural transformation, and also find that productivity difference is the only driver of labor reallo- 
cation across sectors under some assumptions. Mao \& Yao (2012) construct a dynamic general equilibrium model to study structural change across agriculture, manufacturing and services, and choose the productivity effect and the Balassa-Samuelson effect to explain the change of labor share in manufacturing shows hump-shaped form. Święcki (2017) quantitatively investigates the structural change mechanisms, and summarizes that sector-biased technological change is overall the most important channel, which can be used to explain the reallocation of labor across sectors and corresponding growth problems.

Many studies have accessed the importance of information and communication technology (ICT), which is seen as one of the most powerful forces in shaping the twenty-first century (Sturgeon, 2021). Information and communication technology not only can contribute to the labor productivity growth (Ceccobelli et al., 2012), but also can promote the economic growth (Schreyer et al., 2000; Song et al., 2020). The fact that ICT can influence the productivity growth and then can have an effect on the industrial structure change has been confirmed in many researches. Martínez et al. (2010) select a dynamic general equilibrium method to analyze the effect of ICT on US economic growth, and find that technological change is the main force driving US productivity growth, besides, about $35 \%$ of total growth in labor productivity can be accounted for by ICTspecific technological change. Cardona et al. (2013) analyze the quantitative effect of ICT on productivity improvement, and hold that the development of ICT is necessary to foster productivity growth and ICT should be embedded in the process of industrial structure change. Zuhdi et al. (2014) investigate the role of ICT which has played in the process of Japanese industrial structure change by employing a constrained multivariate regression (CMR) model, and highlighting the ICT capital stock as the key driver. Akerman et al. (2015) analyze the effect of broadband on productivity of different skill workers and labor market outcomes, and find that the effects are positive and significant.

"Internet Plus" strategy in China aims to further promote the innovation between ICT industry and other traditional industries. The rise of computer technology attracts close attention since last century, and a lot of relevant studies have discussed the effect of computer technology (Oliner et al., 1994; Jorgenson \& Stiroh, 1995). Now as the vigorous development of mobile internet, cloud computing, big data, and Internet of Things (IoT), there are also many researches focus on the significant role of the new information and communication technology. For instance, IoT plays an important role in value creation, technology revitalization and industrial structure adjustment (Caputo et al., 2016; Del Giudice, 2016). With the adoption of new technological trends and applications of the IoT in the industrial systems, the development of industrial IoT (IIoT) is emerging, which can achieve high operational efficiency and increase productivity (Khan et al., 2020).

Among the growing literature on internet technology progress and structural change, several studies are closely related to our paper. Akizawa \& Kijiima (1997) 
investigate how the rise of Internet-based entrepreneurial networks affects the evolution of the Japanese industrial structure. Jiménez-Rodríguez (2012) analyzes the decomposition effect of internet communication technology, and finds that in some European and American countries, internet communication technology has a positive impact on labor productivity, which is conducive to the adjustment of industrial structure of these countries. Hjort \& Poulsen (2019) examine the role of fast Internet on Africa's employment, and find that it can improve productivity and increase job-creation. In addition, fast Internet may transfer employment shares into higher-productivity jobs.

However, only a few researches are designed to directly and quantitatively study the linkage between internet technology and industrial structure change and employment structural transformation. And previous research on internet technology and structural change has rarely identified any mechanisms to account for the interrelations between the penetration of internet technology progress to TFP and labor reallocation. Our results provide additional insights to the analysis of the adjustment for employment structure and our paper is a necessary supplement to previous literatures.

\section{The Model}

In this section, we develop a simple model of the structural transformation following (Duarte \& Restuccia, 2010). At each period, three goods are produced: agriculture, industry and services. The model is driven by one force-internet technology.

\subsection{Production and Internet Technology}

There are three goods produced at each date: agriculture (a), manufacturing $(m)$, and services $(s)$. The production functions of the three goods are given by the following Cobb-Douglas production functions with constant returns:

$$
Y_{i}=A^{\gamma_{i}} A_{i} L_{i}^{\alpha_{i}} K_{i}^{1-\alpha_{i}}, i \in\{a, m, s\}
$$

where $Y_{i}$ is output in sector $i, L_{i}$ and $K_{i}$ are the labor and capital input in sector $i . \quad A^{\gamma_{i}} A_{i}$ is the sectoral TFP, where $A$ is the internet technology parameter and $\gamma_{i}$ is a sector-specific internet technology penetration to sectoral TFP and $A_{i}$ represents the other technology except for the internet technology.

Assuming that labor and capital are freely mobile across sectors, and the factor prices $w$ and $r$ are given. The profit maximization problem of the representative firm can be represented by the following static problem:

$$
\max _{L \geq 0, K \geq 0}\left\{p_{i} A^{\gamma_{i}} A_{i} L_{i}^{\alpha_{i}} K_{i}^{1-\alpha_{i}}-w L_{i}-r K_{i}\right\},
$$

where $p_{i}$ is the price of good $i$.

\subsection{Households}

We assume that the economy consists of an infinitely lived representative 
household of constant size. And the household is endowed with $L$ units of time each period. The per-period utility is given by

$$
u\left(c_{a}, c_{m}, c_{s}\right)=V\left(c_{a}\right)+\frac{1}{\rho} \log \left[b c_{m}^{\rho}+(1-b) c_{s}^{\rho}\right]
$$

where $b \in(0,1), \quad \rho<1$ and $V\left(c_{a}\right)$ is non-homothetic function defined by:

$$
V\left(c_{a}\right)= \begin{cases}-\infty & \text { when } c_{a}<\bar{a} \\ \min \left\{c_{a}, \bar{a}\right\} & \text { when } c_{a} \geq \bar{a}\end{cases}
$$

where $\bar{a}>0$ is a subsistence level of agriculture goods below which the household cannot survive. This feature of preference $V\left(c_{a}\right)$ can lead to the movement of labor away from agriculture in the process of structural transformation.

The household chooses consumption of each good to maximize the per-period utility subject to the standard budget constraint. Formally,

$$
\max _{c_{i} \geq 0}\left\{V\left(c_{a}\right)+\frac{1}{\rho} \log \left[b c_{m}^{\rho}+(1-b) c_{s}^{\rho}\right]\right\},
$$

subject to

$$
p_{a} c_{a}+p_{m} c_{m}+p_{s} c_{s}=w L+r K
$$

where $K$ is the total supplies of capital.

\subsection{Market Clearing}

Market clearing for labor and capital requires that

$$
\begin{gathered}
L_{a}+L_{m}+L_{s}=L \\
K_{a}+K_{m}+K_{s}=K
\end{gathered}
$$

The market for each good produced must clear:

$$
c_{a}=Y_{a} ; c_{m}=Y_{m} ; c_{s}=Y_{s} \text {. }
$$

\subsection{Equilibrium}

A competitive equilibrium is defined in the usual manner as the sectoral factor demands, $\left\{L_{a}, L_{m}, L_{s} ; K_{a}, K_{m}, K_{s}\right\}$, that maximize profits problem (2) given the prices of the goods $\left\{p_{a}, p_{m}, p_{s}\right\}$; the households solve the utility maximization problem (5) by choosing the optimal consumption portfolio $\left\{c_{a}, c_{m}, c_{s}\right\}$. And the markets must clear, (7)-(9) hold.

For the profit maximization problem of the firm, the marginal revenue of the firm is equal to the marginal cost, which implies that the demands of labor and capital satisfy

$$
\frac{\alpha_{i} K_{i}}{w}=\frac{\left(1-\alpha_{i}\right) L_{i}}{r} .
$$

Then the firm's problem can be reduced to

$$
\max _{L_{i} \geq 0}\left\{p_{i} A^{\gamma_{i}} \bar{A}_{i} L_{i}-\frac{w}{\alpha_{i}} L_{i}\right\},
$$


where $\bar{A}_{i}=\left(\frac{1-\alpha_{i}}{\alpha_{i}} \frac{w}{r}\right)^{1-\alpha_{i}} A_{i}$. Thus the price of good $i$ is inversely related to internet technology $A$ :

$$
p_{i}=\frac{w}{\alpha_{i} A^{\gamma_{i}} \bar{A}_{i}}
$$

The feature of $V\left(c_{a}\right)$ implies that $c_{a}=\bar{a}$, therefore, the labor in agriculture is given by

$$
L_{a}=\frac{\bar{a}}{A^{\gamma_{a}} \bar{A}_{a}} .
$$

The share of labor in agriculture declines as internet technology progresses, which is consistent with the actual movement of labor resources in recent years in China (see Figure 1).

The optimal allocation of consumption across manufacturing and service goods requires:

$$
\frac{b}{1-b}\left(\frac{c_{m}}{c_{s}}\right)^{\rho-1}=\frac{p_{m}}{p_{s}}
$$

Noting that $p_{i} c_{i}=\frac{w}{\alpha_{i}} L_{i}$, the share of employment in manufacturing and services satisfies

$$
\frac{L_{s}}{L_{m}}=A^{\left(\gamma_{s}-\gamma_{m}\right) \rho /(1-\rho)} \kappa,
$$

where $\kappa:=\left(\frac{b}{1-b} \frac{\alpha_{m}}{\alpha_{s}}\right)^{1 /(\rho-1)}\left(\frac{\bar{A}_{m}}{\bar{A}_{s}}\right)^{\rho /(\rho-1)}>0$ is a constant. The difference between internet technology penetration in manufacturing relative to services is the source of labor reallocation between these sectors as long as $\rho \neq 0$. The labor movements depend on the substitution effect-the sign of the substitution ratio $\rho$ and the pervasiveness effect-the sign of the difference of internet technology penetrations $\gamma_{s}-\gamma_{m}$.

In summary, we have the following proposition.

Proposition 1 1) The share of labor in agriculture declines as the internet technology progresses.

2) Assuming that the substitution between manufacturing and service goods is too elastic $(0<\rho<1)$, then the internet technology improvements lead to the employment movement from agriculture and manufacturing into services if $\gamma_{s}>\gamma_{m}$; the converse is true if $\gamma_{s}<\gamma_{m}$.

3) Assuming that the substitution between manufacturing and service goods is too inelastic $(\rho<0)$, then the internet technology improvements lead to the employment movement from agriculture and services to manufacturing if $\gamma_{s}<\gamma_{m}$; the converse is true if $\gamma_{s}>\gamma_{m}$. 
This proposition is similar to Proposition 2 in Ngai \& Pissarides (2007), which indicates that a high elasticity of substitution across manufacturing and service goods leads to shifts of employment shares to sectors with high TFP growth.

\section{Pervasiveness Effect and Substitution Effect of Internet Technology}

In this section, we assess the pervasiveness effect and substitution effect of internet technology on the structural transformation in China and we proceed in three steps. First, we measure the internet technology following Solow residual method (Solow, 1957). Second, we use ordinary least squares (OLS) and panel data analysis to classify the relationship of $\gamma_{m}$ and $\gamma_{s}$ in China, which can decide the different pervasiveness effects of internet technology in manufacturing and services. In the end, we will discuss the substitution effect of internet technology.

\subsection{Measurement of Internet Technology}

According to Industrial Classification for National Economic Activities (GB/T 4754-2011) in China, we choose the data from 31 provinces in Sector I: Information Transmission, Computer Services and Software to measure the internet technology in each region. The data of this sector has been published since 2003, we use a panel of 31 provinces for Sector I for the years 2003 to 2018: 1) gross domestic product $Y$ (unit: 100 million yuan): base period of actual GDP in 2000; 2) Labour input $L$ (unit: 10,000 people), the number of employees; 3) capital stocks $K$ (unit: 100 million yuan) is calculated by a perpetual inventory approach:

$$
K_{t}=(1-\delta) K_{t-1}+I_{t-1}
$$

where $\delta=12.1 \%$ constitutes the depreciation rate of capital, and $I_{t}$ represents real gross fixed capital formation for Sector I.

The initial capital stock $K_{2003}$ is defined by

$$
K_{2003}=\frac{I_{2003}}{g+\delta},
$$

where $g=14 \%$ corresponds to the average growth rate of output in Sector I for the sample period (2003-2018).

The data source is from the National Bureau of Statistics in China and Bureau of Statistics in each province. Then we use the standard Solow residual approach to calculate the internet technology progress rate. In particular, denoting as $\mu_{t}$ the growth rate of technical change at date $t$. The annual average of the internet technology progresses $\mu_{t}$ for each province has been shown in Figure 2. We can see that the internet technology develop rapidly in China, the annual average of the internet technology progresses is about 1.11 in China on average (Average value is obtained according to the data in Figure 2). 


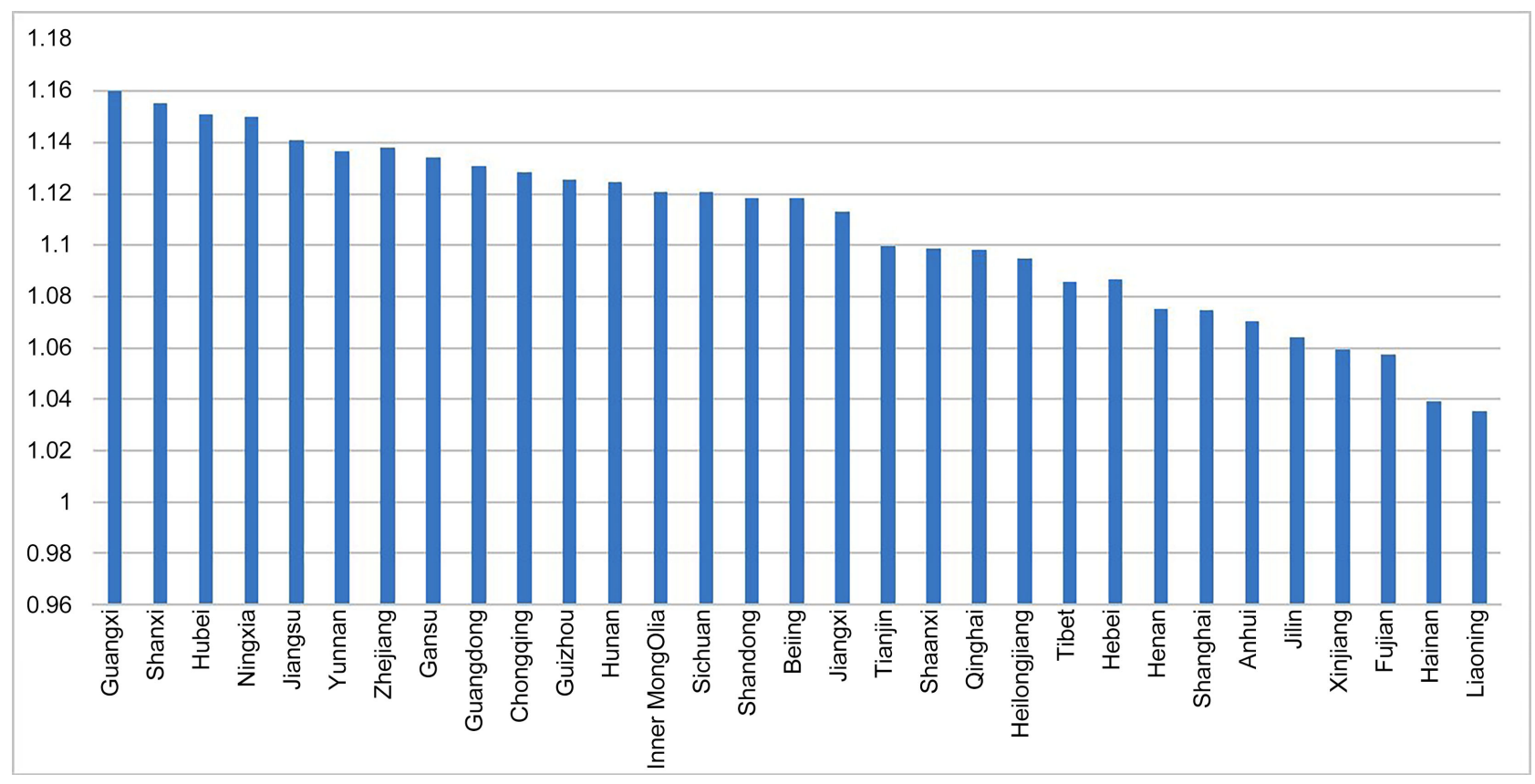

Figure 2. The annual average of the internet technology progresses for 31 provinces 2013-2018.

\subsection{Pervasiveness Effect of Internet Technology}

The pervasiveness effect of internet technology depends on the internet technology penetration $\gamma_{i}$ in each sector. We note that the productivity $\frac{Y_{i}}{L_{i}}=A^{\gamma_{i}} \bar{A}_{i}$, which implies that

$$
\ln \left(\frac{Y_{s} / L_{s}}{Y_{m} / L_{m}}\right)=\left(\gamma_{s}-\gamma_{m}\right) \ln A+\ln \left(\frac{\bar{A}_{s}}{\bar{A}_{m}}\right) .
$$

If the sign of $\ln A$ is significantly positive (resp. negative), then $\gamma_{s}>\gamma_{m}$ (resp. $\gamma_{s}<\gamma_{m}$ ). Otherwise, we have $\gamma_{s} \approx \gamma_{m}$. To examine the sign of $\gamma_{s}-\gamma_{m}$, we estimate a simple regression with the following form:

$$
\ln R P_{i t}=\alpha+\beta \ln A_{i t}+\delta_{i}+\varepsilon_{i t}
$$

where the dependent variable $R P_{i t}$ is the ratio of productivity between services and manufacturing, that is $R P=\frac{Y_{s} / L_{s}}{Y_{m} / L_{m}}, Y$ and $L$ is measured by the gross domestic product and labor input for province $i$ in services and manufacturing sectors. $A_{i t}$ is the time path of internet technology in each province as $A_{i t+1}=\left(1+\mu_{i t}\right) A_{i t}$ and $A_{i 2003}=1$ for all provinces.

Equation (19) is estimated using OLS by pooling together the cross-section and time-series data. Accounting for regional heterogeneity across provinces, the panel data analysis is also conducted in Table 1 . The coefficients of the internet technology level are positive and highly significant in both the fixed effect and random effect models, and which is also significant in the OLS regression. The result means that the internet technology penetration to TFP of services is greater than the penetration of manufacturing. 
Table 1. Estimation of pervasiveness effect of internet technology.

\begin{tabular}{cccc}
\hline & OLS & FE & RE \\
\hline $\ln A$ & $0.0499^{*}$ & $0.0574^{* * *}$ & $0.0572^{* * *}$ \\
& $(0.0286)$ & $(0.0177)$ & $(0.0176)$ \\
\hline \multirow{2}{*}{ Constant } & $-0.518^{* * *}$ & $-0.524^{* * *}$ & $-0.524^{* * *}$ \\
\hline Observations & $(0.0275)$ & $(0.0160)$ & $(0.0576)$ \\
R-sq & 496 & 496 & 496 \\
\hline
\end{tabular}

1. Standard errors in parentheses. $2 .{ }^{* *},{ }^{*}$ representing significance at $1 \%$ and $10 \%$, respectively.

\subsection{Substitution Effect of Internet Technology}

The substitution effect of internet technology is corresponding to the sign of substitution coefficient $\rho$. The substitution between manufacturing and service goods is elastic if $\rho>0$, the converse also holds if $\rho<0$. In Duarte \& Restuccia (2010), the substitution between theses goods is assumed to be low and $\rho$ is given by -1.5 . But our paper contrast with the results of Duarte \& Restuccia (2010), we provide some evidence to support that $\rho>0$.

From the model, the price of goods is inversely related to internet technology by (5). Furthermore, as the internet technology improvement, the price of service goods falls more sharply than the manufacturing goods since $\gamma_{s}>\gamma_{m}$. Due to the availability of the data, we choose the sectors of "home appliances" and "transport and communications" as the typical sectors in manufacturing and services respectively. The consumer price indices (CPI) for these sectors can be regard as the indicators of the prices, and can be normalized CPI to 100 in 2003. The consumptions of home appliances and transport and communications are also the main consumption expenditures for household. We use the per capita consumption expenditure in home appliances and transport and communications to estimate the consumption of manufacturing and service goods, and we normalize the consumption expenditure in each sector is 100 in 2003 expressed by fixed prices. Figure 3 shows that, compared with the sector of home appliances, the consumption of transport and communications increases rapidly as the corresponding price declined. Theses evidence supports that the substitution between manufacturing and service goods is elastic $(\rho>0)$.

The key of heavy industry is industry 4.0 , which is the combination of big data and artificial intelligence. Some cloud computing products replace the workers on the production line, which has the characteristics of service industry and manufacturing industry. For the manufacturing industry directly facing consumers, or light industry, to some extent, it is due to consumers' recognition of the brand premium, which combines with e-commerce channels to build its own brand, resulting in the channel and marketing link accounting for most of the value. For example, the emergence of Mobile Internet promote the development of Internet Transportation such as the generation of taxi and car sharing services, 


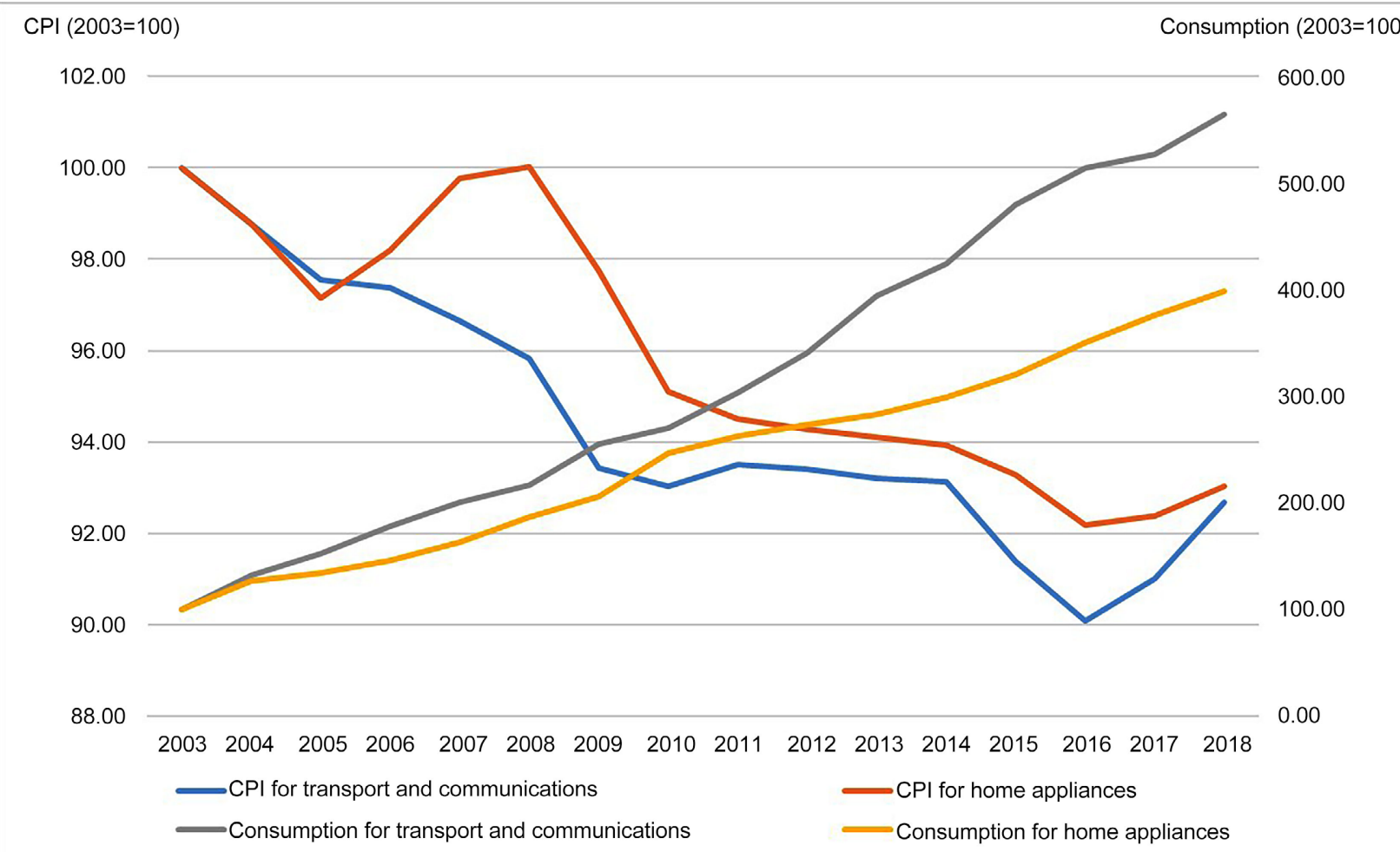

Figure 3. CPI and consumption for transport and communications, home appliances, 2003-2018.

like Uberl, Lyft apps and Chinese apps like DiDi and other service apps. This internet plus traditional transportation provide people with a better way to travel and work. In other words, it creates an alternative to the production and sale of cars. And it also can contribute to the Internet sharing economy development. So vigorous development of internet technology, big data, artificial intelligence, cloud computing and other new technologies makes the substitution between manufacturing and service good is too elastic. In the rest of this paper, we always assume the substitution between manufacturing and service good is elastic $(0<\rho<1)$. In this case, the direction of labor movement depends on the relation between $\gamma_{m}$ and $\gamma_{s}$ according to Proposition 1 .

In conclusion, the pervasiveness effect shows that the internet technology penetration to services is greater than the penetration in manufacturing, and the substitution effect of internet technology shows that the substitution of manufacturing to service goods is elastic. The internet technology improvement should lead to the reallocation of labor from agriculture and manufacturing into services by Proposition 1. The empirical analysis in the next section will further examine this relationship between structural changes and internet technology improvements.

\section{Empirical Analysis}

\subsection{Empirical Design and Data}

The employment shares for agriculture in all 31 provinces are deceasing. This 
feature has been described by Equation (13). We will focus on the ratio of employments between services and manufacturing, denoted by $E S:=\frac{L_{s}}{L_{m}}$. To verify the conclusions obtained by Proposition 1, we estimate the regression of the following form:

$$
E S_{i t}=\alpha+\beta \text { Int }_{i t}+\gamma \text { controls }_{i t}+\delta_{i}+\varepsilon_{i t}
$$

where the dependent variable $E S_{i t}$ is the ratio of employment of services to manufacturing for province $i$ in each year. The explanatory variables $I n t_{i t}$ are the internet technology level for province $i$ in each year, which have been measured in Section 4.

As many factors may influence the ratio of employment $E S_{i t}$, we must control for these factors to overcome the omitted variable bias. Following the previous literature (Bentolila \& Saint-Paul, 2003; Karabarbounis \& Neiman, 2014), we select wage as control variable which is a vital channel for the allocation of labor. And then, we control for education level, as education level may affect labor productivity then affect the movement of labor. Besides, the fixed assets investment and government expenditure may attract the talents. Last but not least, the number of urban population is also an important factor of the employment structure.

So the control variables include wage (Wage), human capital (Hum_cap), investment (Inv), urbanization level (Urb) and government expenditure (Gov_exp). $\delta_{i}$ is the individual effects and $\varepsilon_{i t}$ is an error term. The definitions of variables are detailed in Table 2. The sources of data are from National Bureau of Statistics of China.

\subsection{Empirical Results}

The estimation results by OLS, fixed effect and random effect models are reported in Table 3. As can be seen, the effects of internet technology improvement on structural changes are statistically significant and positive in all the OLS regression, the fixed effect and the random effect models, with the estimated coefficients being around $0.0445,0.0585$ and 0.0507 respectively. The high values of $\chi^{2}$ obtained in the Hausman test suggest that the null hypothesis of random effects is rejected. Thus the effect of internet technology improvement on structural change is 0.0585 as the fixed effect model shows, which is consistent with the conclusion obtained by Proposition 1 .

Due to the pervasiveness effect that the internet technology penetration to services excess the penetration in manufacturing, the productivity growth in services sector is relatively fast, and the prices of service goods falls more quickly than the prices of manufacturing. And because the substitution effect of the internet technology makes the substitution too elastic, the sectors with the higher productivity growth rate can attract a bigger share of labor.

And a complementarity effect is expected between skilled and unskilled workers and internet reasonably. The use of internet and computers can substitute workers who carry out routine tasks, and also can improve working conditions. 
Table 2. Measurement of variables.

\begin{tabular}{cc}
\hline Variables & Measurement \\
\hline ES & Ratio of employment in service to manufacturing \\
Int & Internet technology level calculated by Solow residual method in Section 1 \\
Wage & Log of the average annual wage in urban areas \\
Hum_cap & Proportion of the population with a college degree or above in total population \\
Inv & Ratio of total investment in fixed assets to total GDP \\
Urb & Proportion of urban population to total population \\
Gov_exp & Ratio of local fiscal expenditure to total GDP \\
\hline
\end{tabular}

Table 3. The impact of internet technology on employment structural transformation.

\begin{tabular}{|c|c|c|c|}
\hline & OLS & $\mathrm{FE}$ & $\mathrm{RE}$ \\
\hline \multirow{2}{*}{ Int } & $0.0455^{*}$ & $0.0585^{* * *}$ & $0.0507^{* *}$ \\
\hline & $(0.0246)$ & $(0.0205)$ & $(0.0218)$ \\
\hline \multirow{2}{*}{ Wage } & -0.1727 & $0.7259^{* * *}$ & $0.4326^{* *}$ \\
\hline & $(0.3193)$ & $(0.1630)$ & $(0.1991)$ \\
\hline \multirow{2}{*}{ Hum_cap } & $2.2761^{*}$ & $2.0499^{* *}$ & $3.3842^{* * *}$ \\
\hline & $(1.2733)$ & $(0.7177)$ & $(0.8453)$ \\
\hline \multirow{2}{*}{ Inv } & 0.2261 & -0.1539 & -0.1157 \\
\hline & & $(0.1011)$ & $(0.1047)$ \\
\hline \multirow{2}{*}{ Urb } & $-3.8978^{* * *}$ & $-2.3822^{* *}$ & $-4.1341^{* * *}$ \\
\hline & $(1.0110)$ & $(0.9319)$ & $(1.3502)$ \\
\hline \multirow{2}{*}{ Gov_exp } & $1.0918^{* *}$ & $1.0917^{* *}$ & 1.0067 \\
\hline & $(0.3763)$ & $(0.5113)$ & $(0.7285)$ \\
\hline \multirow{2}{*}{ Constant } & 3.8972 & $-5.4679^{* * *}$ & $-5.6543^{* * * x}$ \\
\hline & $(3.0936)$ & $(1.2926)$ & (1.4588) \\
\hline Observations & 496 & 496 & 496 \\
\hline R-sq & 0.3242 & 0.3994 & 0.3723 \\
\hline$\chi^{2}$ & & 54.61 & \\
\hline
\end{tabular}

1. Standard errors in parentheses. $2 .{ }^{* *},{ }^{* *},{ }^{*}$ representing significance at $1 \%, 5 \%$ and $10 \%$, respectively.

In recent years, with the rapid development of Mobile Internet, new technologies like Cloud Computing, Artificial Intelligence, Big Data, the Internet of things and etc., the services sector has developed rapidly in China. The combination of "Internet Plus" with the services has bred new ecologies, such as Internet Finance, Internet Transportation, Internet Healthcare, Internet Education and etc. The higher penetration of internet technology to TFP of services leads to increase in employment ratio of services to manufacturing around $0.445 \%$ - $0.585 \%$ in China. 
Overall, the model reproduces the salient features of the employment structural transformation well. As these results illustrate, the model replicates well the patterns of the reallocation of labor across sectors. As can be seen, internet technology adoption has a significant impact on the structure of employment.

\section{Conclusion}

This paper investigates the role of internet technology in the employment structural change under the background of "Internet Plus" in China and presents an empirical methodology to disentangle the reallocation of employment associated with the internet technology progress differences across sectors.

We stress in the analysis that the employment ratio of services to manufacturing depends on the differential internet technology penetration (pervasiveness effect) and the elasticity of substitution between manufacturing and service goods (substitution effect). The substitution effect is instantiated in the substitution between manufacturing and service goods becomes elastic during the development of internet technology. The pervasiveness effect is reflected in the difference of internet technology penetration to sectoral TFP and can be measured by data.

"Internet Plus" represents a new economic form, which gives full play to the internet technology in the optimization of the allocation of production resources. Because of the improvement and development of new infrastructure construction, the penetration of internet technology to TFP of services is more significant than that of the manufacturing. Besides, with the rapid development of internet platform and information and communication technologies, the substitution between manufacturing and service goods becomes too elastic. We also illustrate this point by corresponding sectoral data in China. Based on these facts, the employment movement from agriculture and manufacturing into services has been verified by empirical analysis.

While we estimate the model on Chinese data, the results of the paper are broader in scope, as the internet technology model to account for the movement of labor resources is not limited to the Chinese economy. Further encouraging and supporting the innovation of the internet technology in economic society in various fields should be of high priority on the government's agenda of future economic reforms and could promote the real economy innovation and productivity, and accelerate the employment structural transformation and upgrading.

\section{Funding}

This paper was funded by the Social Science Foundation of Qingdao (No. QDSKL2101029) and by the National Social Science Foundation of China (No. 18CJY008).

\section{Conflicts of Interest}

The authors declare no conflicts of interest regarding the publication of this paper. 


\section{References}

Acemoglu, D., \& Autor, D. (2011). Skills, Tasks and Technologies: Implications for Employment and Earnings. In Handbook of Labor Economics (pp. 1043-1171, Volume 4). Elsevier. https://doi.org/10.1016/S0169-7218(11)02410-5

Acemoglu, D., \& Guerrieri, V. (2008). Capital Deepening and Nonbalanced Economic Growth. Journal of Political Economy, 116, 467-498. https://doi.org/10.1086/589523

Akerman, A., Gaarder, I., \& Mogstad, M. (2015). The Skill Complementarity of Broadband Internet. The Quarterly Journal of Economics, 130, 1781-1824. https://doi.org/10.1093/qje/qjv028

Akizawa, H., \& Kijiima, K. (1997). Internet-Based Entrepreneurial Networking to Evolve the Japanese Industrial Structure. Proceedings of the 1997 PACIS Conference, Brisbane, 1-5 April 1997, 677-690.

Andersen, T. J. (2001). Information Technology, Strategic Decision Making Approaches and Organizational Performance in Different Industrial Settings. The Journal of Strategic Information Systems, 10, 101-119. https://doi.org/10.1016/S0963-8687(01)00043-9

Baumol, W. J. (1967). Macroeconomics of Unbalanced Growth: The Anatomy of Urban Crisis. The American Economic Review, 57, 415-426. http://www.jstor.org/stable/1812111

Bentolila, S., \& Saint-Paul, G. (2003). Explaining Movements in the Labor Share. The B.E. Journal of Macroeconomics, 3, 1-33. https://doi.org/10.2202/1534-6005.1103

Boppart, T. (2014). Structural Change and the Kaldor Facts in a Growth Model with Relative Price Effects and Non-Gorman Preferences. Econometrica, 82, 2167-2196. https://doi.org/10.3982/ECTA11354

Caputo, A., Marzi, G., Pellegrini, M. et al. (2016). The Internet of Things in Manufacturing Innovation Processes: Development and Application of a Conceptual Framework. Business Process Management Journal, 22, 383-402. https://doi.org/10.1108/BPMJ-05-2015-0072

Cardona, M., Kretschmer, T., \& Strobel, T. (2013). ICT and Productivity: Conclusions from the Empirical Literature. Information Economics and Policy, 25, 109-125. https://doi.org/10.1016/j.infoecopol.2012.12.002

Ceccobelli, M., Gitto, S., \& Mancuso, P. (2012). ICT Capital and Labour Productivity Growth: A Non-Parametric Analysis of 14 OECD Countries. Telecommunications Policy, 36, 282-292. https://doi.org/10.1016/j.telpol.2011.12.012

Del Giudice, M. (2016). Discovering the Internet of Things (IoT) within the Business Process Management: A Literature Review on Technological Revitalization. Business Process Management Journal, 22, 263-270. https://doi.org/10.1108/BPMJ-12-2015-0173

Duarte, M., \& Restuccia, D. (2010). The Role of the Structural Transformation in Aggregate Productivity. The Quarterly Journal of Economics, 125, 129-173.

http://www.jstor.org/stable/40506279

https://doi.org/10.1162/qjec.2010.125.1.129

Fagerberg, J. (2000). Technological Progress, Structural Change and Productivity Growth: A Comparative Study. Structural Change and Economic Dynamics, 11, 393-411. https://doi.org/10.1016/S0954-349X(00)00025-4

Foellmi, R., \& Zweimüller, J. (2008). Structural Change, Engel's Consumption Cycles and Kaldor's Facts of Economic Growth. Journal of Monetary Economics, 55, 1317-1328. https://doi.org/10.1016/j.jmoneco.2008.09.001 
Hjort, J., \& Poulsen, J. (2019). The Arrival of Fast Internet and Employment in Africa. The American Economic Review, 109, 1032-1079. https://doi.org/10.1257/aer.20161385

Jiménez-Rodríguez, R. (2012). Evaluating the Effects of Investment in Information and Communication Technology. Economics of Innovation and New Technology, 21, 203-221. https://doi.org/10.1080/10438599.2011.561998

Jorgenson, D. W., \& Stiroh, K. (1995). Computers and Growth. Economics of Innovation and New Technology, 3, 295-316. https://doi.org/10.1080/10438599500000008

Jorgenson, D. W., \& Timmer, M. P. (2011). Structural Change in Advanced Nations: A New Set of Stylised Facts. The Scandinavian Journal of Economics, 113, 1-29. https://doi.org/10.1111/j.1467-9442.2010.01637.x

Jorgenson, D. W., Ho, M. S., \& Stiroh, K. J. (2008). A Retrospective Look at the Us Productivity Growth Resurgence. Journal of Economic Perspectives, 22, 3-24. https://doi.org/10.1257/jep.22.1.3

Karabarbounis, L., \& Neiman, B. (2014). The Global Decline of the Labor Share. The Quarterly Journal of Economics, 129, 61-103. https://www.jstor.org/stable/26372544 https://doi.org/10.1093/qje/qjt032

Khan, W., Rehman, M., Zangoti, H., Afzal, M., Armi, N., \& Salah, K. (2020). Industrial Internet of Things: Recent Advances, Enabling Technologies and Open Challenges. Computers \& Electrical Engineering, 81, Article ID: 106522. https://doi.org/10.1016/j.compeleceng.2019.106522

Kongsamut, P., Rebelo, S., \& Xie, D. (2001). Beyond Balanced Growth. The Review of Economic Studies, 68, 869-882. http://www.jstor.org/stable/2695912 https://doi.org/10.1111/1467-937X.00193

Kuznets, S. (1973). Modern Economic Growth: Findings and Reflections. The American Economic Review, 63, 247-258. http://www.jstor.org/stable/1914358

Li, F. Y., Frederick, S., \& Gereffi, G. (2019). E-Commerce and Industrial Upgrading in the Chinese Apparel Value Chain. Journal of Contemporary Asia, 49, 24-53. https://doi.org/10.1080/00472336.2018.1481220

Mao, R., \& Yao, Y. (2012). Structural Change in a Small Open Economy: An Application to South Korea. Pacific Economic Review, 17, 29-56. https://doi.org/10.1111/j.1468-0106.2011.00570.x

Martínez, D., Rodríguez, J., \& Torres, J. L. (2010). ICT-Specific Technological Change and Productivity Growth in the US: 1980-2004. Information Economics and Policy, 22, 121-129. https://doi.org/10.1016/j.infoecopol.2009.07.001

Ngai, L. R., \& Pissarides, C. A. (2007). Structural Change in a Multisector Model of Growth. The American Economic Review, 97, 429-443. https://doi.org/10.1257/aer.97.1.429

Oliner, S. D., Sichel, D. E., Triplett, J. E., \& Gordon, R. J. (1994). Computers and Output Growth Revisited: How Big Is the Puzzle? Brookings Papers on Economic Activity, 1994, 273-334. https://doi.org/10.2307/2534658

Schreyer, P. et al. (2000). The Contribution of Information and Communication Technology to Output Growth: A Study of the G7 Countries. Technical Report OECD Publishing.

Solow, R. M. (1957). Technical Change and the Aggregate Production Function. The Review of Economics and Statistics, 39, 312-320. https://doi.org/10.2307/1926047

Song, Y. W. et al. (2020). Can Industry-University-Research Collaborative Innovation Efficiency Reduce Carbon Emissions? Technological Forecasting and Social Change, 157, 
Article ID: 120094. https://doi.org/10.1016/j.techfore.2020.120094

Sturgeon, T. J. (2021). Upgrading Strategies for the Digital Economy. Global Strategy Journal, 11, 34-57. https://doi.org/10.1002/gsj.1364

Święcki, T. (2017). Determinants of Structural Change. Review of Economic Dynamics, 24, 95-131. https://doi.org/10.1016/j.red.2017.01.007

Zuhdi, U., Mori, S., \& Kamegai, K. (2014). Statistical Analysis of Influences of ICT on Industrial Structure Changes from 1985 through 2005: The Case of Japan. Journal of Computers, 9, 1291-1299. https://doi.org/10.4304/jcp.9.6.1291-1299 